\title{
Les hereves de la poesia de Carmelina Sánchez-Cutillas (o sobre la fractura entre generacions literàries)
}

\section{The heiresses of the poetry of Carmelina Sánchez-Cutillas (or about the fracture between literary generations)}

\author{
Begoña Pozo-SÁnchez \\ begona.pozo@uv.es
}

Universitat de València

\begin{abstract}
Resum: L'obra poètica de Carmelina Sánchez-Cutillas ha trobat, al llarg del temps, dificultats a l'hora de ser transmesa. Malgrat l'ocultació sistemàtica de la seua producció i els obstacles per poder accedirhi, les poetes actuals -en general des de la recerca individual i amb un esforç considerable- han pogut amerar-se de la seua poètica i defensar-la com un referent literari. Per a evidenciar aquest procés de recuperació dels referents femenins, hem realitzat una enquesta a vint poetes del panorama poètic actual al País Valencià. A través de les seues reflexions i aportacions hem pogut construir el camí pel qual han transitat a l'hora de descobrir l'escriptura lírica de Sánchez-Cutillas però, sobretot, quin ha estat el procés de reconeixement de la criptogínia que, especialment, han patit els discursos creats per les dones.
\end{abstract}

Paraules clau: Carmelina Sánchez-Cutillas, poesia i gènere, poesia catalana actual, genealogies, criptogínia

\begin{abstract}
The poetic work of Carmelina Sánchez-Cutillas has encountered, over time, difficulties in being transmitted. Despite the systematic concealment of her production and the obstacles to access it, current poets -generally from individual research and with considerable effort- have been able to soak up her poetics and defend it as a literary reference. In order to demonstrate this process of recovery of the feminine referents, we have carried out a survey to twenty poets of the current poetic panorama in the Valencian country. Through their reflections and contributions we have been able to construct the path they have taken when discovering the lyric writing of Sánchez-Cutillas but, above all, how has been the process of recognition of the cryptogyny that, especially, the discourses created by women have suffered.
\end{abstract}

Keywords: Carmelina Sánchez-Cutillas, poetry and gender, current catalan poetry, genealogies, cryptogyny

DATA PRESENTACIÓ: 01/05/2021 ACCEPTACIÓ: 14/05/2021 ·PUBLICACIÓ: 01/06/2021 
Begoña Pozo-Sánchez. Les hereves de la poesia de Carmelina Sánchez-Cutillas (o sobre la fractura entre generacions literàries)

\begin{abstract}
Por tanto, ser mujer y catalana, y escritora es un reto fascinante, pero también un compromiso por rescatar del pasado, en ocasiones inmediato una serie de obras y de mujeres que sufrieron -como en todo el mundo- el silencio de una sociedad patriarcal.
\end{abstract}

Marta Pessarrodona

La situació que Marta Pessarrodona descrivia a les pàgines de El País l'any 1980 té, quaranta anys després, una paraula que - per primera vegada- anomena i defineix el fenomen: «criptogínia». El novembre de 2020 l'Acadèmia Valenciana de la Llengua incorporava al Diccionari Normatiu Valencià aquest neologisme creat pocs mesos abans amb la voluntat de fer visible, també i necessàriament des del llenguatge, una realitat força reiterada al llarg de la nostra història i que ens resulta ben fàcil d'identificar perquè, com a dones, ens ha acompanyat sempre, ja que malauradament hem heretat una sistemàtica «ocultació dels referents femenins». ${ }^{1}$

Precisament aquesta crida de Pessarrodona per a rescatar del passat obres i dones que patiren el silenci patriarcal ens esperona a la recerca de les genealogies literàries femenines que, no per pròximes, són en realitat més conegudes. Aquest és el cas de Carmelina Sánchez-Cutillas. Si ens endinsem, en concret, a la seua obra poètica, podem dir que, en general, l'oblit, el desconeixement o la desatenció són inèrcies a les quals s'ha vist sotmesa la recepció de la seua producció lírica, tant al País Valencià com al Principat o les Illes - tot i que al primer sí que s'han publicat, especialment als darrers anys, treballs $i$ estudis que recuperen la seua figura. Segurament aqueixa indiferència majoritària cap a la seua obra per part dels seus contemporanis -lectors, crítics i investigadors- fou un dels elements que determinaren el seu silenci estricte a partir dels anys vuitanta. Convindrà doncs, ara, que ha augmentat significativament el nombre de lectores, crítiques i investigadores, tornar a la seua poesia per tal de saber fins a quin punt ha estat considerada un referent, una mare simbòlica, per a les generacions posteriors de les poetes que, com ella, han patit una triple marginalitat pel fet d'haver nascut dones, de conrear la poesia i, a més, de fer-ho en valencià.

\title{
1. Escriure des de l'atzar d'una triple marginalitat
}

Als anys seixanta, com explica el seu fill, Luis del Romero Sánchez-Cutillas, al llibre recent La meva cambra més estimada. La biblioteca de Carmelina Sánchez-Cutillas (2020), es varen produir tres canvis transcendentals en l'obra de l'autora: l'ampliació de les seues col laboracions sobre temes històrics a diversos mitjans de comunicació, el trànsit del castellà al valencià i l'aparició de l'escriptura poètica.

La primera de les qüestions és important perquè evidencia la seua professionalització dins d'un àmbit intel lectual allunyat del rol de gènere omnipresent, el del ángel del hogar, establert pel franquisme com a espai de reclusió -físic i mental-i de submissió. Desobeir el mandat social i els

\footnotetext{
1 Pozo i Padilla (2019): «Criptogínia: una paraula nova per a un fenomen antic». Aquest fou el primer article on els autors explicaren la creació de la paraula per tal de posar nom al fenomen de la invisibilitat i ocultació de les aportacions de les dones al llarg de la història. L'article va aparèixer a eldiario.es el 5 de febrer de $2020 \mathrm{i}$ es pot consultar al següent enllaç: https://www.eldiario.es/comunitat-valenciana/criptoginia-paraula-nova-fenomen-antic_132_1003396.html
} 
Begoña Pozo-Sánchez. Les hereves de la poesia de Carmelina Sánchez-Cutillas (o sobre la fractura entre generacions literàries)

rols de gènere que encotillaven els desitjos i anul laven la llibertat i la voluntat de les dones no era fàcil en una dictadura on es menyspreava la dona, es criminalitzava la cultura i es prohibia qualsevol expressió en una llengua que no fos l'espanyola. Segurament un panorama com aquest no era l'ideal per a poder desenvolupar els interessos intel lectuals, lingüístics o creatius de qualsevol escriptor; menys encara per a les escriptores. En aquest context sociocultural, el fet d'escriure de forma regular en premsa i, a més a més, de canviar de llengua fou, sense cap mena de dubte, una aposta valenta i decisiva per part de Carmelina Sánchez-Cutillas. Com ella mateixa escrivia a una de les cartes citades a l'assaig del seu fill:

És molt difícil conrear la nostra llengua ací a València. La ciutat està totalment castellanitzada. La societat rebutja aquell qui escriu en valencià. I uns i altres no fan més que dir qué lástima que esto lo bayas escrito en valenciano. Tanmateix jo resseguiré el meu camí, perquè soc massa enterca (Del Romero 2020: 39).

L'obstinació de l'autora per escriure i, sobretot, la decisió d'escriure en valencià va estar motivada, per una banda, per les connexions amb el cercle intel lectual amb el qual es relacionava des de ben menuda gràcies a la figura de l'avi matern -destacat bibliòfil i personatge clau en la seua formació tant intel lectual com lingüística- i també per les seues relacions amb el món universitari; per altra banda, perquè com ella va deixar escrit al seu esbós de currículum: «Pregue, somnie i fins i tot maldic en valencià, però per culpa del destí no vaig néixer a Altea, ni a València, ni a Alacant. Malgrat lo qual sóc plenament mediterrània» (Del Romero 2020: 35). La seua connexió conscient i profunda amb la llengua va esclatar als ulls del públic lector amb la publicació de Matèria de Bretanya l'any 1976. El reconeixement unànime per part de la crítica feren d'aquest llibre de memòries una de les fites més importants de la narrativa en català al País Valencià de l'últim terç del segle XX i, en conseqüència, el seu èxit com a escriptora va estar focalitzat sobre la seua obra narrativa -de voltatge, és clar, altament poètic. Tanmateix, Carmelina Sánchez-Cutillas confessava a les seues cartes l'estima pel seu vessant poètic -oposat, en general, a la incomprensió dels seus contemporanis- perquè, com afirma Del Romero, «es considerava abans de res poeta» (2020: 178). Per tant, la percepció que tenia l'autora sobre la mateixa obra palesava un biaix significatiu respecte a la recepció de la seua obra lírica, tal com ho evidencien les seues paraules en una carta a la seua amiga Roser Matheu l'any 1970: «És possible que jo siga poeta: si vosté ho diu i ho repeteix acabarà per ficar-m’ho al cap malgrat la gent que em diu que no sé res de poesia» (Del Romero 2020: 42). Aquestes no foren les úniques paraules on l'autora es lamentava de l'escàs ressò de la seua poesia als anys setanta, com trasllada clarament al seu epistolari: «A pesar de todo, existe un sector en Valencia que no me considera escritora. Seguramente no he sabido enfocar mi afición de escribir y así trabajo más que otros pero con menos provecho publicitario» (Del Romero 2020: 43) o, encara amb més determinació, quan afirma en un qüestionari amb contundència que «la crítica no m’ha tractat per cap costat» (Del Romero 2020: 178).

Com hem comentat adés, els canvis als quals es va enfrontar com a escriptora als anys seixanta donaren com a fruit nombrosos articles de caràcter històric $i$, el que ens interessa especialment

SCRIPTA, Revista internacional de literatura i cultura medieval i moderna, núm. 17 / juny 2021 / pp. 540 - 560 ISSN: 2340-4841 · doi:10.7203/SCRIPTA.17.20923 
Begoña Pozo-Sánchez. Les hereves de la poesia de Carmelina Sánchez-Cutillas (o sobre la fractura entre generacions literàries)

per a la nostra recerca, la publicació dels seus primers llibres de poemes en valencià: Un món rebel (1964) i Conjugació en primera persona (1969), tots dos editats per l'autora després d'haver-los presentat, sense èxit i amb certa polèmica, al Premi València de Poesia convocat per la Diputació de València. Segons l'autora, foren llibres bessons pel que feia a la recepció, caracteritzada en ambdós casos pel silenci: «'afonà en el mateix silenci que abans havia ofegat els crits d’Un món rebel» (Del Romero 2020: 41). Aquest silenci fou una constant també després de la publicació dels dos llibres posteriors, Els jeroglifics i la pedra de Rosetta (1976) i Llibre d'amic e amada (1980). Serà, doncs, en les raons d'aquest silenci -les quals provocaren el seu mutisme definitiu- on haurem de detenir-nos per tal de comprendre millor la figura de Carmelina Sánchez-Cutillas dins la seua època i, sobretot, quin ha estat el significat de la seua obra per a poetes de les generacions posteriors que, en molts casos, l'han considerada un referent.

\section{Aproximació a la subalternitat de la poesia de Carmelina Sánchez-Cutillas}

El silenci de la crítica i el lament de l'autora sobre el fet de no ser considerada com a escriptora són dos aspectes que es troben directament relacionats i orbiten al voltant d'una qüestió fonamental: la recepció de l'autoritat (lat. auctorĭtas, -ātis) que, en aquest cas concret, depèn d'una autoria (lat. auctor, -ōris) femenina. Aquesta última no és una qüestió menor. Per això és pertinent tenir en compte la proposta teòrica de Kimberlé Crenshaw (2016) i del seu concepte «interseccionalitat», que descriu el fenomen pel qual cada individu pateix opressió o ostenta privilegi sobre la base de la seua pertinença a múltiples categories socials.

Abans hem parlat de la posició de subjecte que ocupava la figura de Carmelina Sánchez-Cutillas com a dona, poeta i valenciana. Dins d'aquesta triple condició subalterna hi ha un altre element que accentua la seua marginalitat: la identitat lingüística. Precisament és Lluís Alpera qui, en referència a una altra poeta contemporània, Maria Beneyto, afirma que: «ben dissortadament, és pràctica habitual de certs sectors del "mandarinisme principatî" silenciar -o bé camuflar dins petits capítols subsidiaris- obres o autors en relleu de la perifèria dels Països Catalans» (1996: 9). I a continuació estableix una sèrie d'interrogants que, exactament igual, serien extensibles a l'obra de Carmelina Sánchez-Cutillas: «Fins quan durarà aquesta injustícia? Quan abastarem l'status d'escriptors eurocatalans, sense cap gravamen per l'origen perifèric?» (1996: 9). Aquestes reflexions d'Alpera són ben pròximes a d'altres que, precisament des del Principat, apunten en la mateixa direcció. Maria Mercè Marçal i Lluïsa Julià identifiquen dos binomis sobre els quals s'ha articulat la construcció del discurs històric -i, és clar, canònic- de la literatura/poesia catalana: selecció/exclusió i centre/ perifèria. La interrelació de tots dos -sense oblidar que el segon és sempre el terme minoritari, secundari i negligible - ha provocat, segons les autores: «la posició nuclear de la poesia escrita per l'home», «la centralitat de la Catalunya oriental -especialment Barcelona-» i «l'entronització (...) d'una estètica principal per damunt d'altres considerades secundàries» (2006: 41). Des d'aquesta tradició d'estudis crítics feministes, Maria Lacueva insisteix al seu assaig, Les dones fortes, en dues inèrcies que són decisives per a la configuració de les genealogies literàries femenines: per una 
Begoña Pozo-Sánchez. Les hereves de la poesia de Carmelina Sánchez-Cutillas (o sobre la fractura entre generacions literàries)

banda, «la inèrcia que duu a la invisibilitat de les autores empobreix enormement la percepció de la pròpia tradició literària» (2019: 17); per altra banda, la inèrcia que «tendeix a ocultar autores i autors provinents de comarques diferents a les de la Catalunya oriental». Totes dues, com afirma aquesta investigadora, minven «significativament el potencial del sistema literari català» (2019: 17). En la mateixa línia profunditza Anna Cacciola quan apunta que:

\begin{abstract}
al descentramiento físico y psicológico sufrido por las mujeres durante la represión franquista y su ideología machista se suma, en el caso de las escritoras valencianas, la marginalidad a la cual las condena la historiografía dentro del proceso cultural catalán. La marginación parece ser la característica de toda la literatura de autoría femenina, por ser tratada como un «aparte» en la crítica y en la historiografía literaria, y por tener una tradición literaria, independiente de la masculina, de la cual proceden temáticas, estéticas y retóricas (2019: 288).
\end{abstract}

La marginalitat identificada per Cacciola respecte a les autores valencianes ja havia estat també comentada anys enrere per Lluís Alpera (2004), un dels pocs investigadors que, de forma constant, va acostar-se a l'obra de Carmelina Sánchez-Cutillas. Les seues paraules són ben eloqüents a l'hora de mostrar l'estat de la qüestió:

L'estudi i avaluació global de la literatura de dones al País Valencià és un dels temes que reclamen una urgència que els crítics $i$ professionals de la literatura van ajornant sine die. Per ignorància, per menyspreu o per peresa. $\mathrm{O}$ potser perquè deixen els homes que aquest col letiu siga estudiat per alguna representant de les mateixes escriptores -creadores o crítiques literàries- com és pràctica generalitzada en qualsevol literatura (204: 37).

Tant les paraules d'Alpera com les de Cacciola mostren una tendència gaire habitual als estudis i a les recerques sobre obres d'autoria femenina: la recuperació de les baules d'aquesta cadena fragmentada d'autoritat que rebem com a història de la literatura està sovint lligada exclusivament a l'esforç d'escriptores i investigadores. De fet, les editores Júlia Benavent, Elena Moltó i Silvia Fabrizio-Costa, al seu volum monogràfic dedicat a Las mujeres, la escritura y el poder assenyalen que:

Las voces de las mujeres del pasado, transmitidas por sus escritos, son rescatadas y acompañadas por otras mujeres que, a su vez, además de recuperar del silencio muchos y hermosos testimonios, ofrecen el suyo, suma de su voz y del eco de otras mujeres, en una reflexión también por escrito, plasmada en estos artículos. La propuesta del monográfico se ofreció a todos, hombres y mujeres, y fue secundada por mujeres, excepto en un solo caso. No es una anécdota ese singular hecho, como tampoco lo es que los artículos aquí reunidos sean un mapa en el espacio y en el tiempo de una realidad hecha a pinceladas, tan finas, de trazo tan delicado, que apenas se percibe y se conoce. No son, ya lo sabemos todos y todas, los trazos seguros y duros de un tatuaje en un brazo rudo y curtido, sino la tenue y transparente piel de quien se expone poco al sol, de quien se recoge a menudo entre las paredes silenciosas de la casa. Con todo, la voz es clara y firme. Tiene el timbre nítido, expresa un mensaje inequívoco, a lo largo de los siglos y, contra todos los obstáculos, de forma constante, ininterrumpida (2012: 9-10). 
Begoña Pozo-Sánchez. Les hereves de la poesia de Carmelina Sánchez-Cutillas (o sobre la fractura entre generacions literàries)

Així doncs, aquesta cadena constant suposa una labor tant de reconeixement com de recuperació que travessa prèviament el territori del desconeixement, quan no el de l'ocultació i la criptogínia -com ha demostrat l'acadèmica, escriptora i feminista Joanna Russ en la seua coneguda obra Cómo acabar con la escritura de las mujeres (2019). Per tant, des de la posició d'investigadora/lectora, poeta i valenciana no podem sinó sentir-nos interpel lades per l'obra de les dones que, abans de nosaltres, s'han enfrontat amb valentia i fermesa al repte de l'escriure en una llengua resistent contra tot pronòstic: expressar-se públicament en valencià en aquell moment era una provocació envers una societat opressora, conservadora i profundament masclista. Aquest deure nostre -que convindria compartir amb normalitat amb els nostres col legues- ens permetrà, a poc a poc, completar el mosaic fragmentat que hem rebut com a herència d'un saber incomplet i desarticulat, amb la voluntat de construir un coneixement molt més complet i global que mostre la importància de determinades obres i figures clau per a la construcció d'unes genealogies, les de les dones, que, fins ara, sempre s'han vist mutilades perquè, com apunten Lacueva i Herrero: «hablar de invisibilidad es hablar de un síndrome hereditario, y perpetuado, en el ámbito de las letras femeninas valencianas» (2016: 67). De fet, les reflexions aportades per dues de les poetes enquestades, Susanna Lliberós i Aina Garcia-Carbó, apunten en la mateixa direcció:

La poesia escrita per homes sempre ha estat posada en primer terme i ha deixat en una situació
de marginalitat la poesia escrita per les dones. Un altre factor crec que va ser, com ho és encara,
el geogràfic, allò de la perifèria en què es converteix el País Valencià en relació a Catalunya
(Susanna Lliberós).

Són elles, les oblidades de la meua terra, de la meua llengua, les qui més reivindique perquè crec que així també he de fer-ho. Doble -o triple- «menyspreu» per ser dona, valenciana i amb més o menys recorregut literari (Aina Garcia-Carbó).

El sentit de la nostra recerca haurà de dirigir-se, doncs, cap a la reconstrucció de l'auctoritas perquè, com manifesta Mary Beard (2018) al seu assaig Mujeres y poder, l'autoritat ha estat un espai tradicionalment negat al discurs de les dones i, per tant, s'ha eliminat així qualsevol possibilitat perquè s'afermaren. En la seua anàlisi de la realitat heretada, Mary Beard es mostra implacable: «en lo relativo a silenciar a las mujeres, la cultura occidental lleva miles de años de práctica» (2018: 12). Si ens centrem en el desconeixement de la tradició literària femenina i la seua repercussió en la falta d’autoritat social de les dones, Ana López-Navajas i Ángel López García-Molins ja mostraven la seua valoració sobre aquest tema, avançant i reforçant les futures tesis de Beard:

\footnotetext{
A lo largo del siglo XX se han producido avances hacia la igualdad entre hombres y mujeres en varios ámbitos [...] Sin embargo y a pesar de estos avances, en la actualidad las mujeres aún se encuentran lejos de ver reconocida su autoridad social, es decir, su legitimación social como individuos de pleno derecho y eso se convierte en uno de los más graves impedimentos para el acceso a espacios de poder ya que ese acceso va unido al reconocimiento social. La autoridad social -la auctoritas latina-, lo que entendemos como el saber socialmente reconocido, está unida al ejercicio del poder, la potestas. Potestas que, por lo pronto, no ostentan las mujeres. Esta
} 


\begin{abstract}
falta de autoridad social está asentada en el desconocimiento que existe de las contribuciones que a lo largo de la historia han hecho las mujeres a la cultura y al desarrollo humano. Y el desconocimiento de esta tradición de saber femenino es la consecuencia de la práctica exclusión de las mujeres de los referentes sociales que conforman nuestra visión de mundo y nuestra cultura. Esta exclusión, «el hecho de que las mujeres no pasamos a lo escrito», está ya analizada en teoría feminista (Redondo, 2001: 207) y constituye un hecho indiscutible hoy en día. Sobre todo, está ligada a la ausencia de las mujeres que se puede observar en los textos que definen nuestra tradición cultural, entre los que destacan, por su importancia, los manuales de la ESO (2012: 27).
\end{abstract}

Malgrat el panorama de marginalitat i manca d'autoritat que acabem de descriure respecte a les obres produïdes per autores, en general, i per autores valencianes de postguerra en particular, convé no oblidar tampoc els reconeixements o esforços que s'han fet, principalment al País Valencià i en temps recents, per tal de posar en valor l'obra de Carmelina Sánchez-Cutillas; especialment amb les activitats difoses a partir de l'Any Carmelina de l'AVL -com, per exemple, feminaris d'estudis sobre la seua obra, elaboració de material didàctic per a batxillerat, creació d'una novel la gràfica i d'exposicions o la producció per À Punt del documental Carmelina, mar i cel-, que tindran com a excepcional punt i final l'edició de l'obra completa de l'autora a càrrec de Maria Àngels Francés i Joan Borja. Tampoc hem d'oblidar, però, que sempre hi ha mirades excepcionals que abasten una visió més completa del panorama poètic i són capaces de percebre i, alhora, transmetre la importància de les herències literàries. És el cas de Dolors Miquel (2006) o Enric Cassasses (2009). Aquests dos poetes catalans, referents imprescindibles de la poesia catalana dels anys setanta, reconeixen públicament la qualitat literària de Carmelina Sánchez-Cutillas quan consideren la seua obra com «uns dels cims de la literatura catalana del Segle d'Or, que és el XX com tothom sap» (Cassasses 2009). El punt de connexió entre aquests dos poetes i l'obra de l'autora valenciana rau, precisament, com identifica Anna Esteve, en «'actitud moderna i rebel que traspua per l'obra de Sánchez-Cutillas i que se summa a altres atractius, com ara la potència d'una llengua literària que excel leix en diferents registres» (2017: 30). Serà, essencialment, també aquesta actitud la que trobarem com a lligam essencial entre les poetes valencianes actuals -que han participat a la nostra enquesta_ ${ }^{2}$ i la figura de Carmelina Sánchez-Cutillas.

2 L'enquesta s'ha dirigit a quaranta poetes actuals del País Valencià, de totes les edats, amb obra publicada i amb trajectòria reconeguda per la crítica, els premis, els estudis i/o les antologies. En varen respondre vint, els noms de les quals s'indiquen al cos de l'article. Aquesta és una primera aproximació a l'estat de la qüestió; posteriorment caldrà ampliar l'estudi a les poetes del Principat i les Illes -on encara és més desconeguda perquè, com indica Àngels Gregori a les seues respostes: «a totes les poetes de la nostra generació ens pertany reivindicar-la i difondre-la com cal. Ací, però també al Principat o a les Illes, que és una autèntica desconeguda». Incorporem ací les deu preguntes que traslladàrem a les poetes actuals, per tal d'establir la seua connexió amb l'obra poètica i amb la figura de Carmelina Sánchez-Cutillas: 1. Quan entrares en contacte per primera vegada amb l'obra de Carmelina? Fou d'una forma casual o alguna persona et va recomanar la seua lectura? Recordes els motius i/o l'entorn que provocaren la recomanació? 2. Després de la seua lectura, es va convertir per a tu en un referent de la poesia de postguerra en català? En tenies d'altres referents femenins en aquell moment? Quins eren i en quines llengües? 3. Quan la llegires, quins elements innovadors o originals, perceberes a la seua obra? Quins elements l'apropaven a l'escriptura d'altres dones de la seua època o quins l'allunyaven? Consideraves que era una poètica que tenia el mateix valor que les obres dels seus companys de generació?

SCRIPTA, Revista internacional de literatura i cultura medieval i moderna, núm. 17 / juny 2021 / pp. 540 - 560 ISSN: 2340-4841 · doi:10.7203/SCRIPTA.17.20923 
Begoña Pozo-Sánchez. Les hereves de la poesia de Carmelina Sánchez-Cutillas (o sobre la fractura entre generacions literàries)

\section{Carmelina Sánchez-Cutillas: referent literari de poetes valencianes actuals?}

Les reflexions de l'apartat anterior ens col loquen en una situació precària pel que fa al reconeixement i la transmissió de les obres de les poetes valencianes de postguerra. Tanmateix, com afirma Lacueva, podem dir que les poetes actuals no comencen de zero perquè: «d'escriptores valencianes n’hi hagut, al llarg de la història, i si ara mateix no funcionen com a referents literaris col lectius és perquè se'ls ha negat la possibilitat de ser reconegudes com a part integrant de patrimoni cultural valencià» (2013: 23).

Des d'aquesta perspectiva crítica, la qüestió que ens interessava esbrinar per a la nostra recerca era si l'obra poètica de Carmelina Sánchez-Cutillas -recordem ací que, com s’ha demostrat als diversos comentaris del primer apartat, ella es considerava essencialment poeta- s'havia convertit en un referent literari per a les poetes valencianes actuals. Per tal de dur endavant aquesta investigació consideràrem que era necessari preguntar directament a les poetes actuals sobre la seua relació amb l'obra de Carmelina Sánchez-Cutillas. Per tal de tenir una visió tant completa com fos possible, ens posàrem en contacte amb més de quaranta poetes de tot el territori i de totes les edats. La nòmina de les poetes que respongueren voluntàriament l'enquesta és, per ordre alfabètic de cognom, la següent: Lola Andrés (València,1961); Maria Carme Arnau (Alfara, 1968); Mercé Claramunt (Puçol, 1964); Mercè Climent (Alcoi, 1981); Christelle Enguix (París, 1971); Alba Fluixà (Alzira, 1988); Maria Fullana (València, 1958); Isabel Garcia Canet (Pego, 1981); Aina Garcia-Carbó (Castelló de la Plana, 1993); Àngels Gregori (Oliva, 1985); Gràcia Jiménez (L'Arena, 1957); Imma López Pavia (Llanera de Ranes, 1962); Susanna Lliberós (Vila-real, 1973); Imma Mànyez (Catarroja, 1959); Begonya Mezquita (Sagunt, 1968); Josepa Montagut (Montcada, 1955); Anna Montero (Logroño, 1954); Teresa Pascual (Grau de Gandia, 1952); Isabel Robles (Ciudad Real, 1948) i Rosa Roig (Sueca, 1962).

Si parem atenció a les dates de naixement de les poetes, podem establir diversos grups en funció de la seua edat, ja que aquest serà l'element clau que determinarà les seues vivències històriques, les relacions interpersonals, la formació acadèmica i, en general, les seues possibles lectures i referents -així com la possible coincidència en el temps respecte a les dates de publicació dels poemaris de Sánchez-Cutillas, entre 1964 i 1980. Entre la nòmina de poetes comptem amb una poeta nascuda al final dels anys quaranta, Isabel Robles (1948); sis nascudes als anys cinquanta -Teresa Pascual (1952), Anna Montero (1954), Josepa Montagut (1955), Gràcia Jiménez (1957), Maria Fullana (1958)

4. Amb el pas del temps, l'has fet teua? S'ha convertit en un referent per a tu i per a la teua obra? La consideraries (o no) i per què una poeta canònica? 5. Quines obres, poemes o versos destacaries en funció de la influència que han suposat per a la teua escriptura? 6. Quina opinió tens sobre la poesia en català al País Valencià feta per dones durant la postguerra? Consideres que ha estat difosa -en la seua època i amb posterioritat- amb la mateixa intensitat i visibilitat que la dels poetes? Per quins motius? 7. Com definiries la teua relació amb la poètica de Carmelina Sánchez-Cutillas? 8. Recomanaries la seua obra a les lectores i lectors actuals? Per quines raons? 9. Penses que la seua obra poètica ha estat reconeguda -i en quina mesura- per les generacions posteriors? I, en concret, per la teua? 10. Espai lliure per a qualsevol comentari, reflexió, etc. que vulgues indicar sobre les poètiques de postguerra, especialment la de Carmelina Sánchez-Cutillas. 
Begoña Pozo-Sánchez. Les hereves de la poesia de Carmelina Sánchez-Cutillas (o sobre la fractura entre generacions literàries)

i Imma Mànyez (1959)-; altres sis nascudes als anys seixanta -Lola Andrés (1961), Imma López Pavia (1962), Rosa Roig (1962), Mercé Claramunt (1964), Maria Carme Arnau (1968) i Begonya Mezquita (1968)-; un parell de poetes dels anys setanta -Christelle Enguix (1971) i Susanna Lliberós (Vila-real, 1973)-; quatre dels anys vuitanta -Mercè Climent (1981), Isabel Garcia Canet (1981), Àngels Gregori (1985) i Alba Fluixà (1988)-i, per últim, Aina Garcia-Carbó, nascuda l'any 1993.

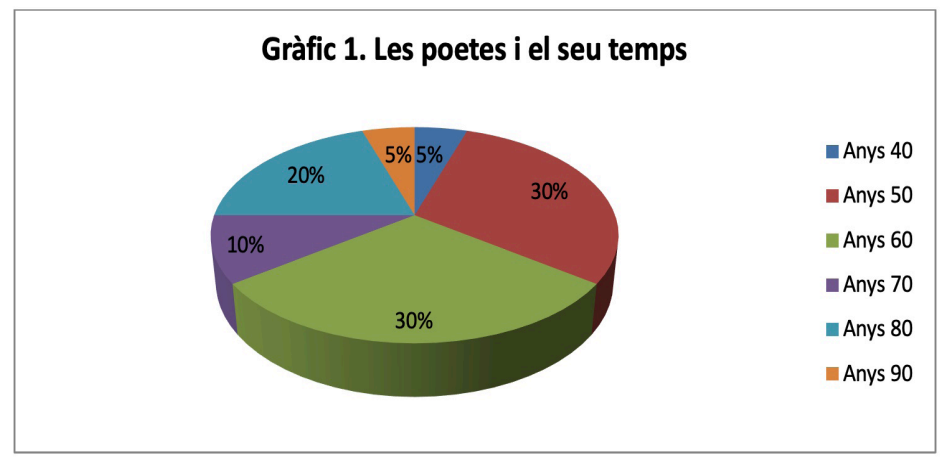

El punt d'inflexió entre els diversos grups podem situar-lo l'any 1970, precisament perquè les poetes nascudes a partir d'aquesta data viuran una societat i una educació força diverses que condicionaran, necessàriament, la seua formació. Ens referim, per una banda, a fites històriques com la culminació del procés de Transició, la instauració de la democràcia i l'aprovació de la Constitució (1978) o el reconeixement de les diverses realitats territorials a través dels estatuts d'autonomia -el del País Valencià fou aprovat al juliol de 1982-; per altra banda, a l'aprovació i implantació de la Llei d'ús i ensenyament del valencià (1983), que fou també un element decisiu a l'hora d'atorgar prestigi social a una llengua i a una cultura que havien estat totalment menyspreades i menystingudes pel franquisme.

Aquesta frontissa temporal és determinant per a entendre el descobriment i l'acostament per part de les poetes actuals a la poesia de Carmelina Sánchez-Cutillas. Seria lògic pensar que, amb l'entrada a les aules del valencià i la incorporació de moltes professores a l'àmbit professional de la docència, alguns referents femenins anaven a ocupar espais més visibles o, si més no, anaven a començar a incorporar-se amb normalitat als llibres de text $i$ anaven a tenir un pes molt més considerable als temaris universitaris. Tanmateix, en funció de les opinions de les poetes que aportarem després, sembla no fou d'aquesta manera. De fet, és ben significatiu constatar que, amb independència de l'edat, les poetes enquestades, com exposarem més endavant, afirmen no haver tingut accés a la figura de la Carmelina poeta a les aules -en cap dels nivells educatius, com constata el gràfic de la pàgina 14-, sinó a la de la narradora de Matèria de Bretanya, precisament l'obra que «ha estat reconeguda, sobretot, per l'èxit de vendes (...) tot i que els estudis al voltant d'aquesta obra són gairebé inexistents» (Lacueva 2019: 21). La qüestió final que apunta Maria Lacueva és fonamental perquè, en el cas de la seua escriptura poètica, malgrat que darrerament hi ha hagut diverses aproximacions a aspectes concrets de la seua obra -entre d'altres: Francés Díez (2015), Bataller Català (2016) o Mira Navarro (2017)-, encara es presenta un panorama escàs d'estudis -en comparació amb l'atenció que ha rebut la seua obra narrativa- que, a poc a poc, va transformant 
Begoña Pozo-Sánchez. Les hereves de la poesia de Carmelina Sánchez-Cutillas (o sobre la fractura entre generacions literàries)

la realitat que denunciava Lluís Alpera a començament del segle XXI quan parlava del silenci de la crítica i l'acadèmia al voltant de l'obra de Carmelina Sánchez-Cutillas:

\begin{abstract}
Algunes reflexions serioses caldrà fer al respecte sobre un col lectiu tant interessant $\mathrm{i}$ tant marginat -sobretot en el passat- com el de les dones. La veritat és que deixant de banda el llarg silenci de l'escriptora, la contribució dels crítics i estudiosos de la literatura a casa nostra no ha estat massa generosa (2000: 22).
\end{abstract}

El silenci de la crítica i dels poetes amb els quals compartia temps històric i preocupacions literàries va generar dinàmiques d'exclusió que, com a conseqüència immediata, suposaren la seua desaparició d'un cànon parcial i patriarcal. Aquesta inèrcia va seguir al llarg dels anys i, com un allau de neu, va ocultar la poesia de l'autora. De fet, no és casual que la major part de les poetes que han participat a l'enquesta consideren que han arribat tard a la seua poesia i, quasi sempre, passant primer per l'obra narrativa. Transcrivim ací alguns dels testimonis que ho corroboren:

La poesia en aquell moment era quasi tota l'escrita pels homes. Però, tant Matèria de Bretanya com
Solitud, de Caterina Albert (Víctor Català), significaren un allau de preguntes i d'emocions. Crec que
van ser, juntament amb els llibres de Carme Riera i Mercè Rodoreda, les primeres lectures d'autores
que m'impressionaren profundament. El coneixement de la seua poesia vindria després (Lola Andrés).

La poesia era, al meu entendre, camp dels homes. Al País Valencià Casp -al seu moment-, Joan Valls, Joan Fuster i Vicent Andrés Estellés ho omplien tot (Josepa Montagut).

Totes les forces del valencianisme cultural, possiblement per qüestions conjunturals, es concentraven en popularitzar l'extens treball poètic d'Estellés, i la seua figura, passant desapercebudes altres poètiques originals i valuoses, no sols la de CSC. Tot fruit d'una situació lingüística, política i social anòmala que ens ha llastrat, reduint-nos els referents culturals (Gràcia Jiménez).

Farà uns 30 anys. Vaig llegir Matèria de Bretanya i em va agradar molt; el trobí a l'institut on treballava. La poesia la vaig descobrir molt més tard (Maria Fullana).

Després de la lectura, Matèria de Bretanya es va convertir en una obra de referència i d’inspiració, que em va acostar a la poesia de Carmelina Sánchez-Cutillas, en concret al poemari Els Jeroglifics i la pedra de Rosetta (Mercè Claramunt).

Als 15 o 16 anys vaig llegir Matèria de Bretanya. Era una de les lectures de batxillerat, va ser, per tant, indicada pel professor de valencià. Vaig estar anys sense tornar-la a llegir, fins que vaig buscar poemes feministes per algun motiu que ara no recorde i la vaig redescobrir, en esta ocasió com a poeta (Susanna Lliberós).

Llegia bàsicament en català. Però sobretot llegia prosa. Vaig arribar a «fixar-me» en la poesia bastant més tard (Rosa Roig).

Naturalment tenia el mateix valor que les obres dels seus companys però no se li donava ni tan sols visibilitat en cap lloc (Teresa Pascual).

Fou durant els anys de l'Institut. Matèria de Bretanya era una de les lectures en català que teníem a casa. La meua germana me la va recomanar i la vaig llegir. Després vingueren el versos (Begonya Mezquita). 
Begoña Pozo-Sánchez. Les hereves de la poesia de Carmelina Sánchez-Cutillas (o sobre la fractura entre generacions literàries)

Si tenim en compte tant aquestes citacions com les dades de totes les aportacions que ofereixen les respostes de les poetes a l'enquesta, podem establir el següent gràfic -on s'observa clarament com el primer contacte amb l'obra de Carmelina Sánchez-Cutillas s'ha produït majoritàriament a partir de la prosa, en concret de la seua «novel la única» Matèria de Bretanya (Borja, 2010: 97).

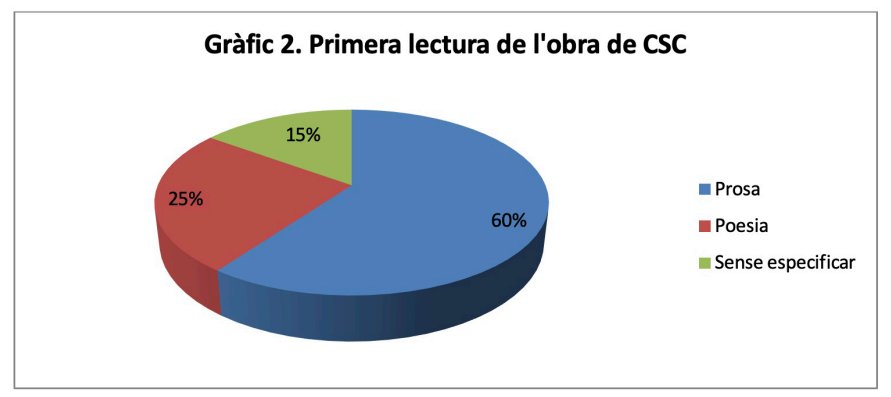

De la mateixa manera que hi ha coincidència pel que fa al descobriment posterior de la poesia de l'autora -qualificat en nombroses ocasions per les poetes enquestades com a clarament tardàrespecte a la seua prosa; també hi ha unanimitat quan reflexionen al voltant dels mecanismes que possibilitaren el seu contacte amb l'obra poètica de Carmelina Sánchez-Cutillas. Com apareix al gràfic 3, dedicat a la identificació del primer contacte amb la poesia de l'autora, en la major part dels casos l'acostament a la poesia es va produir bé de forma autodidàctica -sobretot en les poetes de més edat, generalment guiades per la recerca de veus de dones des de l'activisme polític i el feminisme-, bé per recomanacions, més o menys casuals, d'altres lectors o per la presència de l'autora a les biblioteques familiars o públiques. A partir de les respostes de les poetes copsa que cap d'elles manifeste que va accedir a la lectura de la poesia de l'autora a través de l'ensenyament -com s'ha comentat anteriorment.

En realitat la lectura de la seua poesia va ser posterior. La novel la va tindre tant d'èxit que era el referent més a mà de la seua obra. Personalment, no va ser per a mi un referent de la poesia de postguerra en català, sinó un referent de la poesia contemporània escrita per dones valencianes, des del feminisme, pels finals dels anys setanta i els vuitanta (Isabel Robles).

Vaig llegir Matèria de Bretanya, quan es va editar. No me'n recorde de qui va ser la recomanació, però era un llibre de gran popularitat, així que segurament em vaig assabentar pels mitjans de comunicació. L'obra poètica la vaig conèixer molt després per l'edició que va fer el Consell Valencià de Cultura, l’any 97 (Gràcia Jiménez).

Sí, una casualitat. Vaig anar a comprar-me el poemari de Rosa Leveroni i el llibreter em va recomanar a Carmelina Sánchez (Maria Carme Arnau).

Crec que la primera aproximació a l'obra poètica de la Carmelina fou l'any 1992 i va ser fruit de l'atzar. Començava a llegir poesia en català i cada setmana anava a la biblioteca i me'n tornava a casa carregada amb una desena de llibres. No recorde que ningú me’n parlés de la seua obra poètica, tan sols em sonava com a autora de Matèria de Bretanya (Christelle Enguix). 
Begoña Pozo-Sánchez. Les hereves de la poesia de Carmelina Sánchez-Cutillas (o sobre la fractura entre generacions literàries)

Un amic, Rafael Xambó, sociòleg i músic, va considerar que era el moment per a regalar-me dos llibres importants de la seua biblioteca personal (...). Em va regalar Un món rebel (...) i Conjugació en primera persona (Isabel Garcia Canet).

Preparant un recital per a commemorar el 8 de març a Alzira l'any 2014, mon pare em va recomanar el poema «La nostra rebel lió». El vaig llegir i em va impactar (Alba Fluixà).

De Carmelina recorde Matèria de Bretanya, de la Facultat de Filologia, una de les primeres lectures en valencià que recorde. I la seua poesia l'he llegida molt més tard. Només conec alguns poemes del seu Llibre d'Amic e Amada i he llegit complet el poemari Jeroglifics i la pedra de Rosetta fa molt poc, me’l va recomanar Manel Rodríquez-Castelló (Imma López Pavia).

Amb tot, la primera qui va oferir-me un llibre de Carmelina, va ser ma mare (...) I durant aquest període, no recorde exactament quan, va ser ma mare qui em va presentar i regalar l'obra de Carmelina. En aquell moment, crec que no tenia quasi referents femenins en el món de la poesia (si més en narrativa) (Aina Garcia-Carbó).

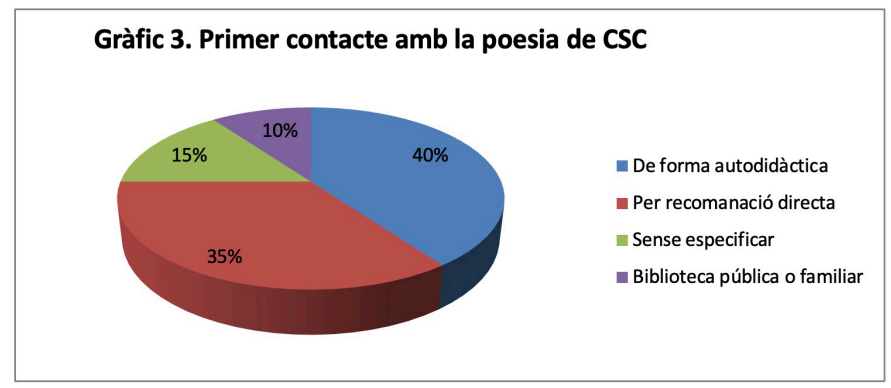

Les respostes de les poetes enquestades evidencien una transmissió anòmala de l'obra de Carmelina Sánchez-Cutillas que, per una banda, ha estat fruit de nombrosos entrebancs socials i culturals i, per altra banda, s'ha produit gràcies a l'atzar, les amistats o les recomanacions literàries. Tot plegat, com ja hem apuntat a les pàgines anteriors, es va generar una dinàmica d'exclusió de la seua poesia respecte dels espais públics d'autoritat com foren, per exemple, la negació del reconeixement literari a través de premis -fet que va suposar l'autoedició dels dos primers poemaris, sense el paraigua editorial-, la manca de reconeixement de la crítica o la falta d'estudis i monografies -tendència que s'ha vist modificada els darrers anys- o l'oblit de la seua producció poètica dins l'àmbit de l'ensenyament. Aquestes circumstàncies, que a hores d'ara podem definir com una criptogínia evident, foren negatives per a la transmissió de la seua poètica i, per tant, la varen desplaçar com a possible referent literari. De fet, aquesta dinàmica és identificada per les poetes més joves que han participat a l'enquesta com un fenomen que encara ha condicionat la seua formació acadèmica. D'aquesta manera expliquen Isabel Garcia Canet, Mercè Climent i, sobretot, Aina Garcia-Carbó la manca de referents femenins al llarg dels seus estudis:

Ara n'està més reconeguda, però per exemple, jo que vaig fer Filologia Catalana a la Universitat de València, no la vaig estudiar (Isabel Garcia Canet). 


\begin{abstract}
$\mathrm{Ni}$ a l'escola ni a l'institut me la van mencionar mai. Tampoc a la universitat quan vaig fer Filologia Hispànica $\mathrm{i}$ tenia tres assignatures de Llengua i Literatura Catalanes. Per a mi ella mai no ha estat un referent de la seua època. Sí en canvia altres escriptores, com ara Caterina Albert, Mercè Rodoreda, Isabel-Clara Simó o Carme Riera. Però ja veus, només una d'elles valenciana (Mercè Climent).

En un primer moment, sempre tenim més homes que dones com a referents perquè és el que se'ns ensenya quan estem estudiant a l'escola o a l'institut (vull pensar que a la Universitat això canvia perquè no es segueix un llibre de text on estranyament se'ns menciona), o fins i tot perquè se'ls publicava més a ells que a elles. I per tant, arriba un moment en la vida de qualsevol dona, en qui és ella, a partir de la seua curiositat, qui ha de buscar d'entre les pedres eixos referents femenins, que sembla que estiguen soterrats i silenciats dins el món literari i en la vida. Això sí, una vegada comences a indagar et trobes tot un món de dones, silenciades, que ni sabies que existia i llavors, et sents malament $i$ penses 'per què sempre nosaltres?', 'em passarà a mi això també?', 'quines i quantes seran les qui ningú recorda?', 'servirà d'alguna cosa el que faig i escric?', 'interessarà el meu punt de vista, la meua expressió, el que jo cree?’... (Aina Garcia-Carbó).
\end{abstract}

Les aportacions de les poetes més joves fan palesa la dificultat actual a l'hora de rebre una formació literària igualitària. De fet, que l'obra de poetes com Carmelina Sánchez-Cutillas siga encara de difícil accés impedeix que el seu mestratge puga produir-se de forma natural. Aquesta situació, que hauria d'haver estat superada amb el pas del temps, és molt similar a la que identificaven les poetes més grans quan descrivien la seua realitat lectora i la manca real de referents, pel que feia a l'obra de poetes valencianes en aquell moment. Afortunadament eren grans lectores i tenien d'altres referents femenins estrangers que contribuïren -en moltes ocasions a través de les seues pròpies traduccionsa l'obertura del diàleg literari entre diverses tradicions poètiques. Tanmateix és inevitable constatar com la realitat més pròxima, la de les poetes que escrivien el món i exploraven les possibilitats del llenguatge en la seua llengua materna, continua, anys després, silenciada també per a les poetes actuals. Per això, la criptogínia que ha patit, entre d'altres, l’obra poètica de Carmelina SánchezCutillas és un clar exemple de les dificultats viscudes per les poetes actuals a l'hora d'arribar a conèixer les genealogies femenines de poetes valencianes:

No tenia en aquells moments referents femenins en català. Sols en castellà i no femenins, llevat de les poques poetes que vam llegir en castellà com Rosalia de Castro (Teresa Pascual).

En aquells moments, gairebé tots els meus referents femenins eren estrangers, a part les poetes catalanes del moment, Maria Mercè Marçal, Marta Pessarrodona. (...) En el meu cas, no va afavorir la meua recepció el fet que, malauradament i inevitablement, es trobara a l'ombra de poetes tan potents com Vicent Andrés Estellés, sobretot. I bàsicament masculins.(Anna Montero).

Sí, després de la lectura d'aquest poema Carmelina es va convertir en un dels meus referents. En aquell moment tenia altres referents femenins com Maria Mercè Marçal, Safo, Àngels Gregori... Posteriorment he anat ampliant molt més la recerca i la lectura de poesia escrita per dones precisament per a poder tindre més referents (Alba Fluixà).

Tot i que gairebé tots els referents poètics que m’anava formant eren homes (!), recorde que vaig començar a llegir Rosalia de Castro, Montserrat Abelló, Anna Akhmàtova i Marta Pessarrodona (Christelle Enguix). 
Begoña Pozo-Sánchez. Les hereves de la poesia de Carmelina Sánchez-Cutillas (o sobre la fractura entre generacions literàries)

Eren molt més els referents masculins (Espriu, Martí Pol, Estellés, Valls...), però, clar, estaven Rosalía de Castro, Gabriela Mistral, Gloria Fuertes, Emili Dickinson, Silvia Plath, Maria Mercè Marçal, i també vaig descobrir alguna rara avis com Cèlia Vinyas o Maria Ibars... (Gràcia Jiménez).

En la facultat Maria Mercè Marçal va ser la primera poeta en català que recorde. I per referències de professors i d'estudiosos de la literatura de Postguerra com Josep Ballester a Clementina Arderiu i Maria Beneyto (Imma López Pavia).

Jo tenia altres referents femenins en aquell moment com ara, la poesia nord-americana: Anne Sexton, Sylvia Plath, Maxine Cummin, Denise Levertov, Adrienne Rich, per exemple, a les quals llegia en anglés o més tard en alguna traducció al castellà. I en l'àmbit català, MariaMercè Marçal, la qual era llegida àmpliament en el món militant del feminisme (Isabel Robles). Com a referents en català, tenia sobretot Maria Mercè Marçal (Maria Fullana).

La poesia en aquell moment era quasi tota l'escrita pels homes (...) El coneixement de la seua poesia vindria després. També començàrem a descobrir poetes com Anne Sexton, Sylvia Plath, Emyli Dickinson, etc; o les joves que començaven a publicar en castellà en els 80, com Blanca Andreu, per exemple (Lola Andrés).

La recerca d'escriptores en aquell moment em va apropar sobretot a Maria Zambrano, Marguerite Yourcenar, Marguerite Duras, Isabel Allende, Alfonsina Storni, Sylvia Plath, Emily Dickinson, Edith Södergran, etc. (Mercè Claramunt).

Sí, llegia molt a Mercè Rodoreda (...) i a Maria Mercè Marçal, Margarita Ballester i Clementina Arderiu (...) i de valencianes de la seua època Maria Beneyto (Isabel Garcia Canet).

Però Carmelina Sànchez Cutillas compartia el meu interés amb la poesia de Maria Beneyto, Clementina Arderiu, Mercé Rodoreda -els sonets i la prosa poètica Viatges $i$ flors un text que sempre m'acompanya- i, sobretot, de Maria Mercè Marçal. També coneixia l'obra de Fina Cardona i Marta Pessarrodona (Rosa Roig).

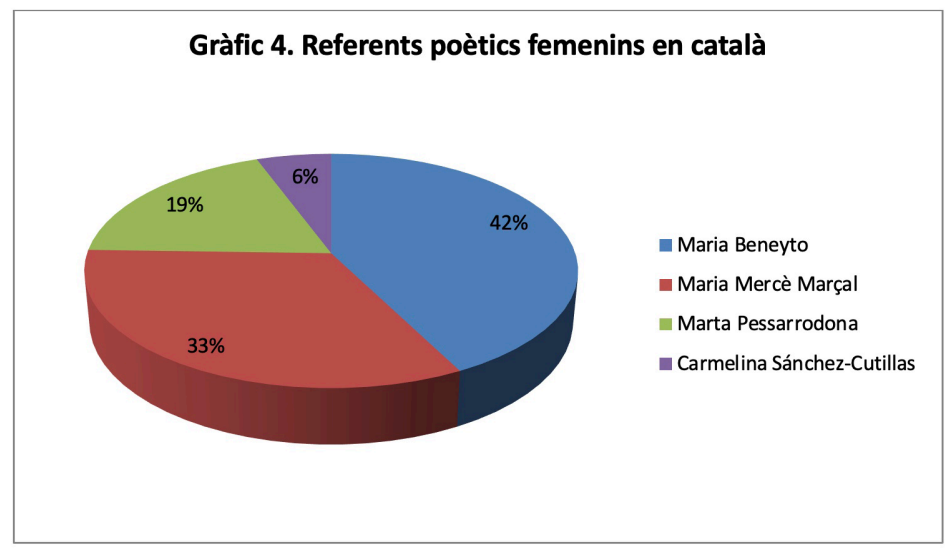

A partir de les seues reflexions, constatem com el referents clàssics de dones poetes són: la valenciana Maria Beneyto (amb nou mencions) i la catalana Maria Mercè Marçal (amb set). Pel que fa a Carmelina Sánchez-Cutillas és anomenada només per dues poetes i la resta de noms de 
Begoña Pozo-Sánchez. Les hereves de la poesia de Carmelina Sánchez-Cutillas (o sobre la fractura entre generacions literàries)

poetes valencianes que apareixen a l'enquesta -Llòria, Ibars, Cardona i Gregori- tenen només una menció. Segons aquestes dades podem afirmar que el coneixement, en general, de les poetes de postguerra valencianes i, en particular, de Carmelina Sánchez-Cutillas ha estat reduit. A més, pel que fa a les poetes més joves, tampoc ha arribat a consolidar-se com a referent. En aquest sentit són clarificadores les paraules de poetes d'edats allunyades com Lola Andrés o Àngels Gregori i Aina Garcia-Carbó:

És clar que sempre he arribat tard a la poesia, dita de postguerra, escrita per dones; sempre. Sobretot durant les últimes dècades del s. XX. Era quasi un miracle trobar els llibres de Sànchez Cutillas, De Beneyto o de Llòria. La difusió ha estat nul la, només durant aquestos últims anys sembla que hi ha un interès per resoldre aquesta injusta alienació i, per tant, reajustar-la $i$ ubicar-la on li pertoca i poder accedir a la seua escriptura (Lola Andrés).

El problema amb Carmelina és l'accés a la seua obra. Fins i tot a dia d'avui ens arriba de forma fragmentària. Pensa que els seus primers llibres se'ls publica ella, i a dia d'avui la majoria de la seua obra poètica és introbable (...) I ara, per unes qüestions o altres -perquè l'AVL ha decretat l'Any Carmelina o perquè el múscul de poetes dones al País Valencià és fort, ric $\mathrm{i}$ ampli i s'emmirallen buscant una genealogia femenina, o perquè des de les universitats s'està estudiant seriosament- és quan més s'està posant sobre la taula la seua obra (Àngels Gregori).

La meua opinió és que la literatura de postguerra feta per dones ha estat completament deixada, abandonada, oblidada o silenciada, que cadascú trobe el sinònim que més li agrade. Trobe nefast que una adolescent, una criatura, una xiqueta, no tinga cap dona com a referent, no tinga una igual com ella a qui puga admirar $\mathrm{i}$ tenir d'exemple, no tinga una dona que li face somniar i la motive per tal que ella també puga desenvolupar-se i arribar lluny, ja siga en l'aspecte literari com en qualsevol altre. Trobe funest que quan s'estudia a l'institut, no es faça menció de ninguna d'elles, com tampoc que es treballe la visió femenina del món, el nostre punt de vista. Se'ns aparta, se'ns deixa al marge, a la perifèria. Considere que no ha estat difosa ni com es mereix, per vàlua, ni de la mateixa manera que els seus companys poetes. Els motius? Una societat patriarcal i a més, en temps de postguerra, una societat patriarcal que castigava la nostra llengua i la nostra cultura. Dues vegades castigada: per ser dona i per escriure en valencià. El patriarcat, la repressió, parla per si mateix (Aina Garcia-Carbó).

Aquests tres exemples - tot i que podrien ser-ne molts més-apunten un canvi de tendència remarcable. De fet, totes les poetes actuals consideren que la poesia de Carmelina Sánchez-Cutillas no ha estat gens reconeguda i malauradament s'ha vist mínimament difosa -tant a la seua generació com a les posteriors-; a més pensem que encara roman encara poc estudiada -l'any 2017 Anna Esteve, al monogràfic que li va dedicar L'aiguadols, conclö̈a amb la necessitat de dur endavant «un estudi complet i de conjunt que impulse, al seu torn, l'edició de les obres completes» (2017: 38) - i tampoc no és de fàcil accés -l'última edició que s'està preparant des de l'AVL pal lia, en part, aquest dèficit, però no resol el problema de no trobar l'autora als catàlegs vius de les editorials ni tampoc el fet de no comptar encara amb una edició crítica. Malgrat aquesta situació d'invisibilitat que ha condicionat la seua recepció i la seua lectura, quasi totes consideren que és una poeta que, una vegada llegida, ha passat a fer part dels seus referents i, per tant, del seu cànon. En aquest punt aportem el testimoni 
Begoña Pozo-Sánchez. Les hereves de la poesia de Carmelina Sánchez-Cutillas (o sobre la fractura entre generacions literàries)

de Mercè Claramunt perquè, tot i que la citació és extensa, permet d’identificar les dificultats que han llastat la difusió de l'obra poètica de Carmelina Sánchez-Cutillas i, en conseqüència, el reconeixement de les seues potencialitats i del seu possible mestratge per a les generacions posteriors.

\begin{abstract}
Quan a considerar-la una poeta cànon diria que el bagatge cultural de Sánchez-Cutillas, la qualitat de la seua literatura, la meticulositat i sensibilitat amb què crea la seua obra, els registres emprats, la riquesa que aporta en la percepció del món que l'envolta, la veu intel ligent i pròpia que descobrim amb la lectura de les seues obres, l'elaboració formal estructurada sobre bases sòlides de cura de llenguatge i exploració de les seues possibilitats, els sentiments que evoca, etc., són totes característiques objectives i objectivables que la situarien en el que necessita una obra per ser considerada cànon i (...), per tant, considere que ha d'estar reivindicada i estudiada al nostre currículum i la considere una poeta canònica.

Però, què impossibilita que entre dintre del cànon literari? (...) Per ser considerada una autora cànon es necessita alguna cosa més, entre d'altres la de visibilitzar-se en bibliografies d'articles i crítiques internacionals i d'ací, o en estudis filològics, tesis, etc., però sobretot una de fonamental, com ho és la traducció a altres llengües.

I perquè tot açò no ha estat possible? Pense que són molts els factors que influeixen. Ser dona no ajudava a sobreeixir en els cercles intel lectuals i cultes de l'època, ni tan sols per transgredir allò per al que se suposava que havies nascut. Escriure en una llengua minoritària en un territori on la llengua dominant és una altra a la que conrees, tancava portes per ser coneguda i per poder difondre l'obra, viure una situació sociopolítica difícil, on és el poder d'una dictadura el que marca les línies definitòries del que es políticament correcte, definitivament marcava un ostracisme difícilment superable.
\end{abstract}

Aquesta reflexió sintetitza de forma ben encertada la realitat literària viscuda per Carmelina Sánchez-Cutillas i, sobretot, l'herència rebuda per les poetes actuals; una herència que podríem qualificar d'incompleta o, en paraules de Maria Fullana a l'enquesta, de «fractura entre generacions». Així doncs, amb la limitació constant de l'accés al coneixement literari i a les obres de les autores, es perpetua el desconeixement dels referents femenins i, per tant, la criptogínia continua mutilant la possibilitat d'aprendre de les mares literàries. Tanmateix, també és cert que hi ha un esforç constant des dels diversos àmbits implicats -recerca, crítica, institucions, editorials i professorat- per tal de visibilitzar la producció literària de les dones. Ara bé, convé assenyalar que l'objectiu prioritari per tal de promocionar la lectura i el coneixement sobre les aportacions de les dones - de totes les èpoques i, en el cas puntual que ens ocupa, de l'obra poètica de Carmelina Sánchez-Cutillas- passa per introduir al currículum els seus noms, per apropar-les a l'alumnat i exposar-los la gran varietat i riquesa de veus que han composat sempre el panorama literari de qualsevol època -tot i que per manca de perspectiva i tradició patriarcal només s’haja posat el focus en la producció dels autors. En aquest punt són ben explícites les paraules de les poetes vinculades a l'ensenyament:

Més com a docent que com a poeta, entenc que res canviarà pel que fa a conéixer i reconéixer la producció poètica de les dones si no entren de forma decidida en el currículum acadèmic $i$ escolar. O entren les autores i la seua obra a les aules, tornaran a desaparéixer, només passe la «moda». Com ja va passar a partir dels anys 90 (Rosa Roig).

SCRIPTA, Revista internacional de literatura i cultura medieval i moderna, núm. 17 / juny 2021 / pp. 540 - 560 ISSN: 2340-4841 · doi:10.7203/SCRIPTA.17.20923 
Con a docent, llig la seua poesia i intente que el meu alumnat, mitjançant la paraula poètica, entenga el seu passat amb la inclusió de totes les dones que es quedaren al marge (Lola Andrés).

Hi ha una tendència a oblidar les escriptores, no reeditar-les, no incloure-les a la història, als llibres de text, apareixen en poques antologies, les invisibilitzen. (...) En aquest moment seria important que fora de lectura obligada, no sols per la qualitat, també perquè l'alumnat tinga una visió de com ha evolucionat la societat (Maria Carme Arnau).

Espere que prompte es puga fer justícia amb la seua obra, incorporant-la a les aules i als espais de difusió literària (Gràcia Jiménez).

Caldria reivindicar-la en l'àmbit escolar, acadèmic i cultural en general. (Begonya Mezquita) A més recomanaria la incorporació al currículum en totes les etapes educatives obligatòries la figura d'escriptores en català del nostre País, en general, i en particular la de Carmelina Sánchez-Cutillas (Mercè Claramunt).

Després de llegir totes les seues aportacions constatem d'allò que intuíem abans de proposar-los l'enquesta: la reivindicació de la poesia de Carmelina Sánchez-Cutillas com a referent de la poesia valenciana de postguerra és una realitat transversal i afecta a totes les poetes enquestades, és a dir, a totes les generacions que conviuen actualment al panorama literari de la poesia en català al País Valencià.. Aquesta situació prové clarament de la consciència que manifesten les escriptores actuals d'haver patit una injustícia cultural motivada directament pel fenomen de la criptogínia, és a dir, per l'ocultació dels referents femenins al llarg de la història. Amb totes les objeccions que es puguen fer al concepte de cànon, perquè «és un producte esbiaixat en molts sentits, que exclou o pot excloure bons autores i autors» -en paraules d'Isabel Robles-; l'aposta per la seua recuperació és unànime. Hi ha reflexions destacables al respecte sobre la necessitat de revisió de la tradició:

(...) hauria de ser inclosa en el lloc on figuren autors i autores que han fet una bona obra, interessant, experimental i innovadora en el seu moment, i que a més perdura amb total actualitat (Isabel Robles).

(...) tot i que és sempre complicat definir què és canònic, jo considere que ella ho podria ser. Té una veu pròpia, significativa, variada i de qualitat literària (Alba Fluixà).

Crec que les lectores i lectors hem de fer el treball -pendent- de tornar a la literatura d'escriptors silenciats per diversos motius (en el cas de les dones, això és evident), per llançar-hi una altra mirada. Potser tindríem més d'una sorpresa (Anna Montero).

Trobe que a més hauria d'haver més treballs dedicats a les canòniques o clàssiques (digues com vulgues) amb introduccions i referències generacionals, estudis comparatius i poemaris, sobretot editar les seues obres o reeditar-les i que foren accessibles (Imma López Pavia).

Cal ser conscient que hi ha una part de la nostra història i de la nostra cultura que, marginada per la crítica, els poders fàctics i la historiografia literària, mostra aquesta marginació i denuncia, en veu alta, la condició de les dones - entre altres qüestions. Cal completar la informació, cal escorcollar en tot allò que s'ha deixat de banda. En resum, resulta impensable que una part de 


\begin{abstract}
la nostra realitat social i cultural, aquella que les dones de la postguerra visqueren i escriviren, no ens acompanye per poder entendre el biaix a què es va sotmetre la cultura d'aleshores (Lola Andrés).

Ara sé que ha estat menystinguda i amagada. I que eixe fet m’ha deixat sense mares simbòliques, a les quals he acabat arribant amb molt d'esforç personal i poques facilitats -llibres editats, estudis, explicacions acadèmiques... Temps perdut que ja no recuperaré. La meua formació com a poeta ha estat mutilada (Rosa Roig).
\end{abstract}

La reivindicació, per part de les poetes enquestades, de tenir accés als referents poètics femenins dins i fora de les aules és una evidència. Cal, des de la seua perspectiva, realitzar tots els esforços necessaris per tal de tenir accés, de forma natural, a les genealogies de poetes i escriptores, sense haver de dedicarli un esforç individual i suplementari que podria suposar la reiteració de les inèrcies que, com ja hem explicat, han ocultat de forma sistemàtica la producció de les dones. Des d'aquesta perspectiva, s'hauria de garantir un compromís educatiu -en tots els nivells formatius i amb tots els agents implicats- que propiciara les accions necessàries per tal de desterrar de manera definitiva la criptogínia a les aules.

\title{
4. Hi ha futur per a la poesia de Carmelina Sánchez-Cutillas?
}

A tall de conclusions podem afirmar que l'obra poètica de Carmelina Sánchez-Cutillas és en aquest moment, per a les poetes enquestades, fonamental. S'ha convertit, malgrat les dificultat generalitzades de l'accés a la seua obra, en una donassa i en una «mare de lletra»-com la defineixa l'enquesta Isabel Garcia Canet-; per tant, la seua obra poètica va adquirint, de forma progressiva, una posició més central dins dels referents de la poesia de postguerra valenciana i va col locant-se en l'espai que li pertoca, com afirma a la seua intervenció Lola Andrés:

Era quasi un miracle trobar els llibres de Sànchez Cutillas, De Beneyto o de Llòria. La difusió ha estat nul la, només durant aquestos últims anys sembla que hi ha un interès per resoldre aquesta injusta alienació i, per tant, reajustar-la i ubicar-la on li pertoca i poder accedir a la seua escriptura.

El canvi de tendència que s'ha produit amb més intensitat durant els darrers anys i, molt especialment, arran de la declaració de l'Any Carmelina per l'AVL -com ham remarcat les poetes a les seues respostes-, situa la recepció de l'obra poètica de Carmelina Sánchez-Cutillas en una posició de major reconeixement -llavors, també de repercussió pel que fa a la presència de la seua veu a l'espai públic. En aquesta direcció apunten les paraules d'Isabel Robles, quan reflexiona sobre les aportacions del feminisme en la recerca de les mares simbòliques:

No puc estar-me de pensar, pel que fa a les poetes, en una relació amb la proposta del feminisme de recuperar les figures de dones obviades, ignorades, invisibilitzades en qualsevol disciplina del saber o la creació. I, vull creure, que, potser, les més joves generacions han aprés per fi que cada generació no ha de començar el seu esdevenir des de zero per a aconseguir el seu lloc 
Begoña Pozo-Sánchez. Les hereves de la poesia de Carmelina Sánchez-Cutillas (o sobre la fractura entre generacions literàries)

en el món en què ha de viure. Que compta amb un llarg camí anterior, amb una història, una tradició, uns assoliments i èxits, dels qual aprendre per a no cometre els mateixos errors, o per avançar i aconseguir una existència millor.

El desig exposat per Isabel Robles, la poeta de més edat, es veu confirmat per les paraules de la poeta més jove, Aina Garcia-Carbó -també mestra de professió:

Senzillament, és que busque -O sempre he buscat- referències en la meua llengua, referències $\mathrm{i}$ exemples de la meua terra, de ma casa, ja que són elles les qui jo aspire a ser algun dia. Són elles, les oblidades de la meua terra, de la meua llengua, les qui més reivindique perquè crec que així també he de fer-ho. Doble -o triple- «menyspreu» per ser dona, valenciana i amb més o menys recorregut literari.

Les connexions que travessen el temps i que, a través de la literatura, lliguen les poetes enquestades de diverses edats $i$ tendències són la prova fefaent de la determinació amb la qual les dones que estimen llegir i escriure estan disposades a no renunciar al passat ni al present, ni tampoc a l'espai públic des del qual defensar totes les veus que sumen i que, gràcies a la tasca incansable d'escriptores, investigadores, crítiques, professores, editores, acadèmiques o traductores, es multipliquen per tal d'apamar un paisatge literari, cultural i social més complet i equitatiu.

L’aproximació a la recepció de la poesia de Carmelina Sánchez-Cutillas, des de la mirada d'aquestes vint poetes valencianes actuals, ha estat la constatació tant d'un descobriment, com d'una negació. A través dels exemples aportats s'ha demostrat que ha existit una contraposició entre les inèrcies rebudes des de la tradició cultural i els esforços renovadors per part d'aquestes poetes. La tensió entre aquestes dues forces ha provocat el descobriment de poètiques amagades -com era el cas de l'obra poètica de Carmelina Sánchez-Cutillas-i, per tant, ha contribuït de forma decidida a la ampliació de les fronteres líriques i de les genealogies literàries. Amb tot, seria convenient recordar que la tasca de recuperació de les figures rellevants del nostre passat literari és un deute que no només pertoca, en aquest cas, a les poetes -O, en general, a les dones que ocupen avui dia espais d'auctoritat i potestas-; sinó que correspon a tota la societat el fet de reivindicar-les per tal d'eliminar la bretxa que, durant massa temps, ens ha limitat l'accés a un coneixement ple.

Tot i que albirem un futur més benèvol en relació al reconeixement públic i literari de la producció de les poetes de postguerra, gràcies especialment als canvis de perspectiva i de model produïts per un increment molt significatiu dels estudis i la dedicació rigorosa a les poètiques més amagades -com sabem, en general, les de les dones-; considerem que encara calen esforços considerables per a facilitar l'accés a les obres d'aquestes autores i, sobretot, incorporar-les a les aules. Si tenim en compte totes les reflexions que hem aportat de les poetes enquestades, podem concloure que sí que hi ha futur no només per a la poesia de Carmelina Sánchez-Cutillas; sinó també per a la de tantes altres poetes silenciades que, amb constància i de forma sistemàtica, van recuperant-se amb la voluntat d'ampliar les fronteres canòniques, perquè com diu Mercè Claramunt a una de les seues intervencions: «Tenim temps i ganes per a fer-ho realitat, no trobeu?».

SCRIPTA, Revista internacional de literatura i cultura medieval i moderna, núm. 17 / juny 2021 / pp. 540 - 560 ISSN: 2340-4841 · doi:10.7203/SCRIPTA.17.20923 
Begoña Pozo-Sánchez. Les hereves de la poesia de Carmelina Sánchez-Cutillas (o sobre la fractura entre generacions literàries)

\section{Bibliografia}

Alpera, L. (1996) «Presentació. Homenatge a Maria Beneyto», L'Aiguadolc, 22, pp. 9-11. . (1997) «Introducció» dins Sánchez-Cutillas, C. Obra poètica, València, Consell Valencià de Cultura.

—_. (2000) «Carmelina S. Cutillas, una gran poetessa als anys 60 i 70», Saó, 244, pp. 22-24.

—. (2004) «Sobre poetes valencians i altres escrits»/3, Barcelona, PAM.

Bataller, A. (2016) «Espais i llocs literaris, conceptes de mediació literària: aplicació als casos de C. Sánchez-Cutillas i M. Vicent», eHumanitas/IVTTRA, 10, pp. 188-207.

Beard, M. (2018) Mujeres y poder. Un manifiesto, Barcelona, Crítica.

Benavent, J. / Moltó, E. / Fabrizio-Costa, S. (2012) «Introducción», Quaderns de Filologia. Estudis literaris, XVII, pp. 9-11.

Borja, J. (2010): «Matèria de memòria», Sarrià. Revista d'investigació i assaig de la Marina Baixa, 4, pp. 96-105.

Cacciola, A. (2019) «Carmelina Sánchez-Cutillas: Deconstrucción y reconstrucción identitaria femenina desde la marginación», Lectora, 25, pp. 287-306. D.O.I.: 10.1344/Lectora2019.25.18.

Cassasses, E. (2009) «Porpra i caretes per als germans», El País 26.02.2009.

Crenshaw, K. (2016) On Intersectionality: Essential Writings of Kimberlé Crenshaw, New York, The New Press.

Del Romero Sánchez-Cutillas, L. (2020) La meva cambra més estimada. La biblioteca de Carmelina SánchezCutillas, València, Vincle.

Esteve, A. (2017) «Un passat on retrobar-se. Memòria i identitat en l'obra poètica de Carmelina Sánchez-Cutillas», L'aiguadolç, 46, pp. 29-40.

Francés Díez, M. À. (2015) «Una travessa pel laberint: Assaig d'interpretació de Elsjeroglifics i la pedra de Rosetta, de Carmelina Sánchez-Cutillas», Caplletra, 58, pp. 9-28. DOI: 10.723/Caplletra.58.7135

Lacueva i Lorenz, M. (2007) “"Jo vinc d'un temps perdut”: escriptores en català al País Valencià durant el franquisme. Breu aproximació», Liquids, 1, pp. 1-14.

- (2013) Elles prenen la paraula. Recuperació crítica i transmissió a les aules de les escriptores valencianes de posguerra: una perspectiva des de l'educació literària, València, Universitat de València.

_-. (2019) Les dones fortes. La narrativa valenciana sota el franquisme, València, Institució Alfons el Magnànim.

Lacueva i Lorenz, M. / Herrero Herrero, M. Á. (2016) «Construyendo las genealogías femeninas literarias valencianas: estado de la cuestión», dins Moszczy ska-Dürst, K., Kumor, K., Garrrido González, A. i Calderón Puerta, A. (eds) Identidad, género y nuevas subjetividades en las literaturas hispánicas, Varsovia, Instituto de Estudios Ibéricos e Iberoamericanos de la Universidad de Varsovia, pp. 67-88. 
Begoña Pozo-Sánchez. Les hereves de la poesia de Carmelina Sánchez-Cutillas (o sobre la fractura entre generacions literàries)

López Navajas, A. / López García, A. (2012) «El desconocimiento de la tradición literaria femenina y su repercusión en la falta de autoridad social de las mujeres», Quaderns de Filologia. Estudis literaris, XVII, pp. 27-40.

Marçal, M. M. / Julià, Ll. (2006): «Diferència i/o normalització: la poesia catalana dels darrers trenta anys», Rels, 8, pp. 39-56.

Miquel, D. (2006) «Peixos sense bicicleta», El País 5.01.2006.

Mira Navarro, I. (2017) «Un feix de coses petites: Els espais de la quotidianitat en Carmelina SánchezCutillas i Vicent Andrés Estellés», L'aiguadolc, 46, pp. 41-54.

Pessarredona, M. (1980) «Ser mujer, catalana y escritora: una meditación», El País 21.11.1980.

Pozo, B / Padilla, C. (2019) «Criptogínia: una paraula nova per a un fenomen antic», eldiario.es 5.02.2019.

Sánchez-Cutillas, C. (1997) Obra poètica, València, Consell Valencià de Cultura.

Russ, J. (2019) Cómo acabar con la escritura de las mujeres, Sevilla, Editorial Dos Bigotes / Editorial Barrett. 